\title{
Pre-Service Teachers' Attitudes Towards Including Students with Moderate Learning Difficulties in Mainstream Schools in the Context of Kuwait
}

\author{
Alenezi Nouf ${ }^{1}$, Alqallaf Bader ${ }^{1} \&$ Zainab Abbas ${ }^{1}$ \\ ${ }^{1}$ College of Basic Education, The Public Authority for Applied Education and Training, Kuwait \\ Correspondence: Alenezi Nouf, College of Basic Education, The Public Authority for Applied Education and \\ Training, Kuwait.
}

Received: June 15, 2019

doi:10.5539/ies.v13n2p11
Accepted: July 25, 2019 Online Published: January 29, 2020

URL: https://doi.org/10.5539/ies.v13n2p11

\begin{abstract}
Inclusive education has become a global trend in the provision of services for students with disabilities. While attitudes towards inclusion have been studied widely in some countries, little research in this area has been conducted in Kuwait. This study responds to this need by researching pre-service teachers' attitudes towards inclusive education. This study examined Kuwaiti pre-service teachers' attitudes towards including students with Moderate Learning Difficulties (MLD) in general education classrooms. Questionnaires were distributed to 452 Kuwaiti pre-service male and female teachers at the College of Basic Education. Several factors, such as teachers' knowledge, were found to be related to pre-service teachers' attitudes towards inclusion. The results of the study indicated that, overall, Kuwaiti pre-service teachers hold positive attitudes towards inclusion.
\end{abstract}

Keywords: inclusion, pre-service teachers, disability, attitudes, MLD

\section{Introduction}

This study is a timely response to the current developments in the provision of educational services for children with disabilities in the context of Kuwait. The success of inclusive education depends largely on teacher's attitudes. This study is the first to examine the attitudes of pre-service teachers' at the College of Basic Education in Kuwait.

Education is a broad concept that involves the student in teaching and learning rather than limiting the student to being only a passive recipient of knowledge; hence, it is an active process of student engagement (Duchesne \& McMaugh, 2018). Salamanca Statement, as one of the significant documents from history, sheds light on the importance of the idea of inclusive education in the field of special education. In the last twenty-five years, the idea of inclusive education has been influencing the world's policies and practices (Ainscow, Slee, \& Best, 2019). Ainscow et al. (2019) discussed the recent evaluation of all the major developments and policy implications to highlight the challenges of inclusion of students with disabilities in mainstream schools. The argument for inclusion in mainstream schools, therefore, involves the fundamental issue of human rights; hence, the principle of inclusion reflects a complex educational ideology.

\subsection{Inclusive Education in Kuwait}

Westwood (2018) indicated that inclusive education is facing challenges in both developing and developed countries. In Kuwait, most disabled students are presently educated in special schools according to their diagnosed disability and only three groups of students with disabilities are educated in special classes in mainstream schools (i.e., children with Down's syndrome, MLD and children with SpLD). The special class setting, known in Kuwait as 'inclusive setting,' is in contrast with the fundamental principle of inclusion "that all children should learn together, wherever possible, regardless of any difficulties or differences they may have" (UNESCO, 1994). According to the Abbas, Almusawi, and Alenezi (2019), understanding and knowledge of the administrators who are providing services for students with disabilities in Kuwait have not been measured sufficiently. Furthermore, UNESCO emphasizes that inclusive education is desired because it promotes equal opportunities in the educational system, providing support to the excluded or marginalized groups in terms of provision of quality education (UNESCO, 2017). Although inclusive education has a long history, its implementation is facing a lot of troubles despite legislative policies (Koutsouris, Anglin-Jaffe, \& Stentiford, 2019). In this regard, inclusion is not 
only one simple dimension, but it also involves four dimensions, namely presence, academic participation, belonging (social participation) and achievement (Norwich, 2013). However, Norwich (2013) identified that conflict can occur among these different dimensions at different levels, specifically, the class level, the school level, the local level, and the national level. Starting at the class level, SEN children can be placed in a mainstream class (i.e., presence), but they may not be participating academically or socially. Second, at the school level, SEN children might attend mainstream school (placement inclusion), but they may not feel that they belong to the school. In other words, although SEN children may attend a mainstream school, they are placed in a special class or unit (academic exclusion). At the local level, SEN children may be placed in a special school identified by the local authority system as an inclusive school. Finally, at the national level, to understand attitudes towards inclusion, researchers need to study and understand the four dimensions of inclusion. This paper attempts to clarify these dimensions in the context of Kuwait. In Kuwait, the government emphasizes only physical inclusion, in other words, moving children with special needs from special schools to mainstream schools. However, it is important to keep in mind that inclusion embodies a range of assumptions about the meaning and the purpose of schools; it is not only about "going" to the mainstream school; instead, it is about "participating" in the mainstream school (Schwab, Nel, \& Hellmich, 2019).

\subsection{Pre-Service Teachers'Attitudes}

Suity (2019) claimed that teachers' preparedness to deal with student diversity in inclusive schools is one of the main aspects of becoming inclusive. The concept of inclusive education is designed to promote democratic principles, values, and beliefs that underpin equality and social justice. A key aspect of effective inclusion is social participation, which is considered one of the key aspects of inclusive schools and is clearly defined in the Index for Inclusion in terms of "the participation in the cultures, curricula, and communities of local schools" (Norwich, 2013). To enable teachers to deal with learners' diversity in mainstream schools, the Salamanca Statement (UNESCO, 1994) argues for governments to consider developing teachers' knowledge to "ensure that, in the context of a systemic change, teacher education programs, both pre-service and in-service, address the provision of special needs education in inclusive schools" (p. x). In this regard, teachers' preparedness to deal with student diversity, in inclusive schools, is one of the main aspects of becoming inclusive (Ainscow \& Miles, 2009). Cooc (2019) highlighted the role of teachers in preparing for the inclusion based on the findings that teachers who have an inclusive setup pay less time to teaching classes as most of the time, they focus on the behavioral issues of the children with special needs. Hence, there is a disparity between teaching a class comprising more students with special needs and teaching other classes.

Pre-service teachers' knowledge is considered as an important factor in the development of inclusive education, and its effects on their self-efficacy and attitudes towards inclusion have been identified in several studies (e.g., Ahsan et al., 2013). For instance, Sharma et al. (2015) investigated the attitudes of 194 pre-service Pakistani teachers (male and female) enrolled in a one-year teacher education program at a government university. Their findings indicated that the participants with training in special education and knowledge of disability legislation and experience with disability showed a higher level of self-efficacy towards teaching within inclusive settings. Other research (e.g., Forlin \& Chambers, 2011; Oswald \& Swart, 2011; Sharma et al., 2009) found that pre-service teachers who had completed teacher education programs focusing on the education of students with disabilities were more willing to include students with special needs in their classrooms. Thus, effective training programs and positive experiences of inclusion may increase positive attitudes and self-efficacy. Swain et al. (2012) examined the change in pre-service teachers' beliefs about and attitudes towards inclusive practices following an introductory special education course. Their results suggested that a special education course, paired with field experience working with students with disabilities, can significantly affect the pre-service teachers' attitudes towards inclusive education. In this regard, pre-service teachers' attitudes towards inclusive practices and their level of teaching self-efficacy have played a significant role in the implementation of inclusive practices in schools. Z. Mngo and A. Mngo (2018) conducted a study to explore the role of training in the positive attitude of teachers towards inclusive education. It has been found that training can enhance the leadership skills of teachers in inclusive education, and it may also increase their positive attitude and self-efficacy; hence, these trained professionals may be more willing to include special children in the class. Alnahdi, Saloviita, and Elhadi (2019) designed a study to measure the attitudes of preservice teachers towards inclusive education in two different countries, Saudi Arabia and Finland. The attitude towards inclusion has been found to differ across cultures. In the sample of Saudi participants, a significant difference in attitudes emerged between individuals of different genders and educational backgrounds whereas the Finnish participants' attitudes did not differ across these variables. The cross-cultural differences in attitude toward inclusion also need to be considered to bring the change at the global level. A great deal of research has sought to examine teachers' attitudes toward the general philosophy of inclusion 
by exploring factors that might influence their attitudes (Jordan, 2018). Furthermore, Jordan (2018) argued that the teacher who accepts his/her responsibility is more likely to maintain a positive attitude towards the special needs students.

A great deal of research has sought to examine teachers' attitudes toward the general philosophy of inclusion while exploring factors that might influence their attitudes (Hassanein, 2010). Early on, Thomas and Zaniecki (1918, cited in Ajzen \& Fishbein, 1980) viewed attitudes as mental processes that determine a persons' actual and potential responses. Allport (1935) defined attitude broadly as "a mental and neutral state of readiness, organized through experience, exerting a directive or dynamic influence upon the individual's response to all objects and situations with which it is related" (p.798). This definition is considered by some researchers as the best-known definition among the early definitions of attitudes because it is rich and comprehensive. This study investigated pre-service teachers' attitudes towards the inclusion of children with MLD. The current definition used in Kuwait considers that MLD students suffer from a lack of mental capacity and have an IQ range of 70-84, resulting in difficulties in academic achievement. However, the policy requires that IQ levels should not be used as the sole basis for diagnosis; it is necessary to strengthen the diagnosis by evaluating academic achievement and psychological, social, and medical aspects (Kuwait Ministry of Education, 2012). Research on pre-service teachers' attitudes towards inclusion of students with disabilities is seen as a fundamental source that can inform teacher education practices in western countries; however, such research is lacking in countries such as Kuwait. Consequently, undertaking similar research in Kuwait will be of value not only for Kuwaiti government policymakers and educators but also for students with disabilities.

\subsection{Study Aim and Questions}

Pre-service teachers' attitudes are very important because they underpin the teachers' professional practice. The key aim of this study was to investigate Kuwaiti pre-service teachers' attitudes towards inclusive education. This is driven by a belief that considering the voice of pre-service teachers is vital for developing the practice of inclusion. To address this aim, the following research question needs to be answered:

What are Kuwaiti pre-service teacher's attitudes toward inclusion?

\section{Methods}

\subsection{Sample}

This research was conducted in the College of Basic Education in Kuwait during the 2018 academic year. Overall, 20929 male and female students were enrolled in the college that year. The college offers a range of courses, with some designed to prepare students to hold teaching jobs in the future. We recruited the participants who are going to pursue a career in the field of education as teachers to measure their attitudes towards inclusion education. This research focused on pre-service teachers only; thus, our population comprised 14128 pre-service teacher students who intend to pursue a teaching career. Of this population, only 484 pre-service teachers participated in this research of whom 32 participants were eliminated because they provided incomplete answers. The final sample in the current study comprised 452 (66 males and 386 females). The age range was 18 to 50 ( $M=22.91$ years, $\mathrm{SD}=4.85$ ). As illustrated in Table 1, the sample of pre-service teachers was divided into three categories, teachers specializing in teaching pupils with $\mathrm{SpLD}$, teachers specializing in teaching pupils with MLD, and teachers specializing in other areas of teaching.

Table 1. Participants' categories based on field specialism

\begin{tabular}{ccccc}
\hline Categories & Frequency & Percent & Valid Percent & Cumulative Percent \\
\hline SpLD & 163 & 36.1 & 36.1 & 36.1 \\
MLD & 100 & 22.1 & 22.1 & 58.2 \\
Other & 189 & 41.8 & 41.8 & 100.0 \\
Total & 452 & 100.0 & 100.0 & \\
\hline
\end{tabular}

\subsection{Instrument}

Consistent with Robson's (1993) claim that a large-scale study is relatively simple and straightforward for investigating phenomena; a questionnaire was designed to obtain the views of the pre-service teachers towards including children with MLD in mainstream schools. The questionnaire was designed to investigate the four main dimensions of inclusion, social inclusion (i.e., items number 8, 10, 20, 21, 23, 24), physical inclusion (i.e., items 6 , 9,12 ), academic inclusion (i.e., items $7,11,22,25$ ), and practicality of inclusion (i.e., items $14,15,16,17,18,19$, 
10,13). The questionnaire was designed based on Norwich's (2013) idea that inclusion is not a simple dimension but rather contains multidimensionality. The multidimensionality of inclusion was also found in the design of the questionnaire used by Hassanein (2010), who examined teachers' perspectives about inclusive education using items measuring social inclusion, academic inclusion, physical inclusion, and additional items to determine the extent to which is it practical to apply inclusive education and the requirements of inclusion. The current study's questionnaire was based on the same dimensions. The questionnaire included 25 items, with most items worded to indicate positive attitudes toward the four dimensions of inclusion. Items $9,12,16,20,22$, and 24 were worded to indicate negative attitudes toward inclusion, so the scores on these items were reversed to be compatible with the other items. The questionnaire used a 5-point scale, ranging from 1 to 5 , with a higher mean score indicated a more positive attitude toward inclusion. Before applying the instrument, a copy was sent to four different academic professors specializing in inclusive education who were asked to review the items and offer feedback. Changes were made based on their feedback. To examine the validity of the questionnaire, the instrument was piloted with 40 pre-service teachers in the College of Basic Education. These students also had the chance to write comments on each item that they believed was not accurate. Regarding internal validity, the results of Cronbach's alpha presented in Table 2 ranged from .482 to .639 . The items with values below .7 were acceptable, as Cronbach's alpha can be affected by the number of items. Scales that include fewer than 10 items tend to have a low Cronbach's alpha (Pallant, 2013).

Table 2. Internal reliability

\begin{tabular}{lclc}
\hline Subscales & N of items & Items & Cronbach's Alpha \\
\hline Social inclusion & 6 & RQ8 -RQ10 -RQ20*-RQ21 -RQ23 -RQ24* & .639 \\
Physical inclusion & 3 & RQ6 -RQ9*-RQ12* & .482 \\
Academic inclusion & 4 & RQ7 -RQ11 -RQ22*-RQ25 & .571 \\
Practicality of inclusion & 6 & RQ14 -RQ15*-RQ16*-RQ17-RQ18 -RQ19 & .534 \\
\hline
\end{tabular}

$\left.{ }^{*}\right)$ refers to reversed items.

\subsection{Data Analysis}

After gathering the data, SPSS was used to calculate the overall score for each dimension and the mean score for each participant. Subsequently, different tests were used to analyze the data. A t-test was used to compare two gender groups (Pallant, 2013). A One-Way ANOVA test was also used to compare the mean scores of the three groups (i.e., pre-service teachers specializing in SpLD, pre-service teachers specializing in MLD, pre-service teachers specializing in other areas of education). Correlation tests, as well as regression tests, were also used to examine the extent to which the four dimensions of inclusion were correlated and could predict each other.

\section{Results}

\subsection{The Total Mean}

The means of subscales were positive, as all were above 3 . The mean of social inclusion and academic inclusion were almost the same (Table 3).

Table 3. Means of the subscales

\begin{tabular}{lccc}
\hline & $\mathrm{N}$ & Mean & Std. Deviation \\
\hline SOCIAL & 452 & 3.66 & .57 \\
PHYSICAL & 452 & 3.23 & .77 \\
ACADEMIC & 452 & 3.67 & .69 \\
PRACTICALITY & 452 & 3.49 & .56 \\
Valid N (listwise) & 452 & & \\
\hline
\end{tabular}

Note. The items were measured on a 5-point scale. High mean scores indicate higher aspirations or greater engagement in informal learning activities; * $\mathrm{p}<.05$.

The mean of academic inclusion, $M=3.67, S D=.69$, and the mean of social inclusion, $M=3.66, S D=.57$, were not significantly different. Adding to that the mean of the practicality of inclusion was also close to that of social and academic inclusion $(M=3.49, S D=.56)$. The high mean of social, academic, and practicality indicates high 
aspirations and engagement in informal learning activities, as opposed to the physical inclusion that had the lowest, although positive, mean $(M=.23, S D=.77)$.

\subsection{T-Test Based on Gender}

An independent-samples t-test revealed no significant differences between the scores of males and females (Table 4 ) in three dimensions (social inclusion, physical inclusion, and academic inclusion). Notwithstanding, males and females differed significantly in the dimension of the practicality of inclusion, $\mathrm{t}(450)=2.13, \mathrm{p}=.03$, with males $(M=3.63, S D=.52)$ scoring higher compared to females $(M=3.47, S D=.57)$.

Table 4. T-test based on gender

\begin{tabular}{llllll}
\hline & Gender & Mean & Std. Deviation & $\mathrm{t}(450)$ & $\mathrm{Sig}$ \\
\hline \multirow{2}{*}{ Social } & Male & 3.67 & .53 & .15 & .88 \\
& Female & 3.66 & .58 & & \\
\multirow{4}{*}{ Physical } & Male & 3.28 & .78 & .66 & .50 \\
& Female & 3.22 & .77 & & \\
Academic & Male & 3.71 & .66 & .60 & .54 \\
& Female & 3.66 & .70 & & \\
\multirow{4}{*}{ Practicality } & Male & 3.63 & .52 & \multirow{2}{*}{2.13} & $.03^{*}$ \\
& Female & 3.47 & .57 & & \\
\hline
\end{tabular}

\subsection{ANOVA Test Based on Participants' Major}

A one-way between-groups analysis of variance was conducted to explore the effect of participants' majors on social inclusion, physical inclusion, academic inclusion, and practicality of inclusion.

Table 5. ANOVA

\begin{tabular}{lcccc}
\hline Dimension & Mean & Std. Deviation & $\mathrm{F}(2,449)$ & Sig \\
\hline Social inclusion & 3.66 & .57 & $4.82 *$ & .008 \\
Physical inclusion & 3.23 & .77 & $5.09 *$ & .006 \\
Academic inclusion & 3.66 & .69 & $5.09 *$ & .007 \\
Practicality of inclusion & 3.49 & .56 & $12 *$ & .000 \\
\hline
\end{tabular}

Note. The items were measured on a 5-point scale. High mean scores indicate higher aspiration or greater engagement in informal learning activities; * $\mathrm{p}<.05$.

Significant differences emerged at the $\mathrm{p}<.05$ level in all dimensions: $\mathrm{F}(2,499)=4.82, \mathrm{p}=.008$, for social inclusion; $\mathrm{F}(2,499)=5.09, \mathrm{p}=.006$, for physical inclusion; $\mathrm{F}(2,499)=5.09, \mathrm{p}=.007$, for academic inclusion; and $\mathrm{F}(2,499)=12$, $\mathrm{p}=.000$ for the practicality of inclusion. Effect sizes, calculated using eta squared, were small for all dimensions $(.021, .022, .022$, and .05 respectively).

\subsection{Post Hoc Tests}

Post-Hoc tests conducted for the four dependent variables indicated no significant differences between SpLD and other groups in all dependent variables. However, the results indicated that the MLD group was significantly different from the SpLD and Other groups in all dependent variables, as illustrated in Table 6. 
Table 6. Tukey HSD

\begin{tabular}{|c|c|c|c|c|c|c|c|}
\hline \multirow{2}{*}{ Dependent Variable } & \multirow{2}{*}{ (I) major } & \multirow{2}{*}{$(\mathrm{J})$ major } & \multirow{2}{*}{ Mean Difference (I-J) } & \multirow{2}{*}{ Std. Error } & \multirow{2}{*}{ Sig. } & \multicolumn{2}{|c|}{ 95\% Confidence Interval } \\
\hline & & & & & & Lower Bound & Upper Bound \\
\hline \multirow{2}{*}{ Social } & \multirow{2}{*}{ MLD } & SpLD & $.22029^{*}$ & .07206 & .007 & .0508 & .3897 \\
\hline & & OTHER & $.16607^{*}$ & .07015 & .048 & .0011 & .3310 \\
\hline \multirow{2}{*}{ Physical } & \multirow{2}{*}{ MLD } & SpLD & $.26133^{*}$ & .09653 & .019 & .0343 & .4883 \\
\hline & & OTHER & $.28460^{*}$ & .09397 & .007 & .0636 & .5056 \\
\hline \multirow{2}{*}{ Academic } & \multirow{2}{*}{ MLD } & $\mathrm{SpLD}$ & $.27371^{*}$ & .08749 & .005 & .0680 & .4794 \\
\hline & & OTHER & $.21082^{*}$ & .08517 & .036 & .0105 & .4111 \\
\hline \multirow{2}{*}{ Practicality } & \multirow{2}{*}{ MLD } & SpLD & $.24416^{*}$ & .06962 & .001 & .0804 & .4079 \\
\hline & & OTHER & $.33013^{*}$ & .06778 & .000 & .1708 & .4895 \\
\hline
\end{tabular}

*. The mean difference is significant at the 0.05 level.

Specifically, the MLD group $(M=3.8, S D=.5)$ differed significantly from the $\operatorname{SpLD}(M=3.59, S D=.61)$ and the other $(M=3.64, S D=.57)$ in social inclusion. Similarly, the MLD group had the highest means for all dependent variables. For the physical inclusion variable, the MLD group scored higher $(M=3.44, S D=.65)$ compared to the $\operatorname{SpLD}$ and Other group $(M=3.18, S D=.83 ; M=3.15, S D=.74$, respectively). For academic inclusion, the MLD group score higher $(\mathrm{M}=3.85, \mathrm{SD}=.67)$ compared to the $\operatorname{SpLD}(M=3.58, S D=.73)$ and other $(M=3.64, S D=.65)$ groups. For the practicality dimension, the MLD group scored higher $(\mathrm{M}=3.72, \mathrm{SD}=.53)$ compared to the $\operatorname{SpLD}(M=3.47$, $S D=.57)$ and other $(M=3.39, S D=.52)$ groups.

Table 7. Correlations among the four dimensions

\begin{tabular}{|c|c|c|c|c|c|}
\hline & & Social & Physical & Academic & Practicality \\
\hline \multirow{3}{*}{ Social } & Pearson Correlation & - & $.543^{* *}$ & $.638^{* *}$ & $.494^{* *}$ \\
\hline & Sig. (2-tailed) & & .000 & .000 & .000 \\
\hline & $\mathrm{N}$ & & 452 & 452 & 452 \\
\hline \multirow{3}{*}{ Physical } & Pearson Correlation & & - & $.558^{* *}$ & $.379^{* *}$ \\
\hline & Sig. (2-tailed) & & & .000 & .000 \\
\hline & $\mathrm{N}$ & & & 452 & 452 \\
\hline \multirow{3}{*}{ Academic } & Pearson Correlation & & & - & $.484^{* *}$ \\
\hline & Sig. (2-tailed) & & & & .000 \\
\hline & $\mathrm{N}$ & & & & 452 \\
\hline \multirow{3}{*}{ Practicality } & Pearson Correlation & & & & - \\
\hline & Sig. (2-tailed) & & & & \\
\hline & $\mathrm{N}$ & & & & \\
\hline
\end{tabular}

The relationships between the four dimensions were investigated using Pearson's product-moment correlation coefficient. The results indicated positive correlations among all dimensions. More specifically, social inclusion largely correlated with physical $(r=543, \mathrm{p}<.01)$ and academic inclusion $(r=638, \mathrm{p}<.01)$; it also moderately correlated with the practicality of inclusion $(r=494, \mathrm{p}<.01)$. Moreover, there was a large correlation between physical inclusion and academic inclusion $(r=558, \mathrm{p}<.01)$. Finally, moderated correlations were found between the practicality of inclusion and both academic inclusion $(r=484, \mathrm{p}<.01)$ and physical inclusion $(r=379, \mathrm{p}<.01)$.

\subsection{Regression}

A regression test was conducted to explore the best predictors for social inclusion. All the assumptions of multiple regressions were checked, and no violation was found. As indicated in Table 8, the three independent variables significantly predicted social inclusion $\left(\mathrm{R}^{2}=.490, \mathrm{~F}(3,488)=143.65, p<.05\right)$. The results of the regression indicated that physical inclusion significantly predicted social inclusion scores, $\beta=.403, t=9.278, p<.05$. The physical inclusion is the largest predictor compared to practicality $(\beta=.240, t=5.827, p<.05)$ and academic inclusion $(\beta=.209, t=5.348, p<.05)$. 
Table 8. Regression for predicting social inclusion

\begin{tabular}{cccccccc}
\hline \multirow{2}{*}{ Variable } & Model & \multicolumn{2}{c}{ Anova } & \multicolumn{4}{c}{ Coefficients } \\
\cline { 2 - 8 } & $\mathrm{R}^{2}$ & $\mathrm{~F}(3,448)$ & $P$ & $B$ & $\beta$ & $t$ & $p$ \\
\hline Physical inclusion & .490 & 143.65 & .000 & .332 & .403 & 9.278 & .000 \\
Academic inclusion & & & & .213 & .209 & 5.348 & .000 \\
Practicality of inclusion & & & & .179 & .240 & 5.827 & .000 \\
\hline
\end{tabular}

\section{Discussion}

The findings showed no significant differences between female and male pre-service teachers' attitudes towards inclusion. This is similar to findings in other studies that found no gender difference in attitudes towards inclusion (Al-Zyoudi, 2006; Majoko, 2016; Sharma, Forlin, \& Loreman, 2007). In the current study, the results showed that all participants have positive attitudes towards inclusion. This result is in line with a recent study conducted by Majoko (2016) who examined pre-service teachers' understanding and attitudes towards inclusion in early childhood education in Zimbabwe, stating that all participants held strong and positive attitudes towards inclusion primarily because of its perceived social benefits.

On the other hand, the findings indicated that MLD pre-service teachers have more positive attitudes towards inclusion compared to other groups (i.e., SpLD and non-SEN pre-service teachers). It is worth mentioning that MLD pre-service teachers' education includes modules about inclusion while the education program for other groups of participants does not include such modules. Thus, it could be argued that the lack of knowledge of and training on inclusion might have affected the attitudes of SpLD and non-SEN pre-service teachers towards inclusion in the current study. Similarly, other studies have found that teachers who had more positive attitudes towards inclusion overall had higher levels of training in special education (Z. Mngo \& A. Mngo, 2018, Forlin et al., 2009; Van Reusen, Shoho, \& Barker, 2000). Similarly, studies have found that those studying postgraduate degrees have the most positive attitudes towards inclusion, as they often study special education or inclusion (Sharma, Moore, \& Sonawane, 2009). Researchers who have designed or analyzed modules on special education and inclusive education have established that the modules improved teachers' attitudes towards inclusion (Carew, Deluca, Groce, \& Kett, 2019; Sharma, Forlin, \& Loreman, 2008; Spandagou, Evans, \& Little, 2008; Subban \& Sharma, 2006).

Lack of knowledge and its effects on the attitudes of pre-service teachers towards inclusion reported in this study are in line with the results of Avramidis and Kalyva (2007) who found that "teachers with further training in SEN and inclusion matters hold significantly more positive attitudes than those with little or no training concerning inclusion" (p. 385). Teachers' knowledge is considered one of the most important factors for successful inclusive education, because it can affect their attitudes towards inclusion. In addition, Toye, Wilson, and Wardle (2019) showed that teachers' knowledge not only affects their attitudes towards inclusion but also minimizes the stigma related to disability. Thus, effective training programs and positive experiences of inclusion could increase positive attitudes and self-efficacy. Additionally, Swain et al. (2012) examined the change in pre-service teachers' beliefs about and attitudes towards inclusive practices following an introductory special education course. The results suggest that a special education course, paired with field experience working with students with disabilities, can significantly affect pre-service teachers' attitudes towards inclusive education. In this regard, in the context of Kuwait, teachers' lack of knowledge about inclusion could be considered as one of the main barriers to inclusion, as the professional training for teachers is the key factor for successful inclusion (Marchesi, 1998). Thus, trends are changing to accommodate the needs of special students in inclusive education setups (Elbeheri et al., 2018).

Although the findings indicate that most of the participants had positive attitudes towards academic and social inclusion more than physical, such results indicate that pre-service teachers are in favor of the four dimensions of inclusion, as all of the measured dimensions had positive scores. This also supports the social model of understanding disability which indicates that inclusive education has built its basis on the assumptions of the social model of understanding disability (Barton, 1997b). In this regard, the social model of understanding disability can affect inclusive educational practices positively, and it can help overcome the structural, environmental, or attitudinal rather than individual barriers to inclusive education, which could enhance the participation and education of all students with disabilities (Alenezi, 2016; Barton, 1997b). One of the key purposes of the social model is to redress oppression and injustice practices towards disabled individuals (Norwich, 2013; Oliver, 1996). The positive attitudes of pre-service-teachers and the social model of understanding disability are considered vital aspects of the successful practice of inclusion. Consequently, the results of this study imply that inclusion can be implemented widely in Kuwait. 


\section{Limitations, Further Studies, and Recommendations}

To better prepare pre-service teachers for inclusive education, this paper recommends the provision of educational workshops and training for pre-service teachers to improve their knowledge of the concept of inclusion. Furthermore, it is recommended that the Kuwait University and the College of Basic Education in the State of Kuwait develop courses or certain programs specially designed for 'inclusive education' to enhance pre-service teachers' knowledge as well as their skills in the area of inclusion and disability.

The survey was conducted with pre-service teachers at the College of Basic Education in the State of Kuwait, thus, the findings may not allow for generalization. Another limitation is that the study's design, data collection, and analyses were mainly quantitative in nature. Based on these limitations, further studies should adopt a qualitative design to explore the actual knowledge and attitudes towards inclusive education. The Salamanca Statement and framework for action recommends and advises the signatory countries that "pilot experiments and in-depth studies should also be launched to assist in decision-making and in guiding future action" (UNESCO, 1994, p. 25). As such, Kuwait needs to respond to these recommendations to be a part of the global trend towards inclusive education. Furthermore, it would be significant to further investigate the attitudes of disabled students towards inclusion as well as their parents. Such studies should help guide the development of education for all in the State of Kuwait.

\section{References}

Abbas, Z., Almusawi, H., \& Alenezi, N. (2019). The self-perceived knowledge of special education administrators in Kuwait. International Education Studies, 12(5), 78-85. https://doi.org/10.5539/ies.v12n5p78

Ahsan, M. T., Deppeler, M. J., \& Sharma, U. (2013). Predicting pre-service teachers' preparedness for inclusive education: Bangladeshi pre-service teachers' attitudes and perceived teaching-efficacy for inclusive $\begin{array}{llll}\text { education. Cambridge Journal of } & \text { 517-535. }\end{array}$ https://doi.org/10.1080/0305764X.2013.834036

Ainscow, M., \& Miles, S. (2009). Developing inclusive education systems: How can we move policies forward? University of Manchester, UK. Chapter prepared for a book in Spanish to be edited by Climent Gine et al. (2009). Retrieved from http://www.ibe.unesco.org/fileadmin/user_upload/COPs/News_documents/2009/ 0907Beirut/DevelopingInclusive_Education_Systems.pdf

Ainscow, M., Slee, R., \& Best, M. (2019). The Salamanca Statement: 25 years on. International Journal of Inclusive Education, 7-8, 671-676. https://doi.org/10.1080/13603116.2019.1622800

Ajzen, I., \& Fishbein, M. (1980). Understanding attitudes and predicting social behaviour. Englewood Cliffs, NJ: Prentice-Hall.

Allport, G. W. (1935). Attitudes. In C. Murchison (Ed.), Handbook of social psychology (pp. 789-844). Worchester, MA: Clark University press.

Alnahdi, G. H., Saloviita, T., \& Elhadi, A. (2019). Inclusive education in Saudi Arabia and Finland: Pre-service teachers' attitudes. Support for learning, 34(1), 71-85. https://doi.org/10.1111/1467-9604.12239

Carew, M. T., Deluca, M., Groce, N., \& Kett, M. (2019). The impact of an inclusive education intervention on teacher preparedness to educate children with disabilities within the Lakes Region of Kenya. International Journal of Inclusive Education, 23(3), 229-244. https://doi.org/10.1080/13603116.2018.1430181

Cooc, N. (2019). Do teachers spend less time teaching in classrooms with students with special needs? Trends from international data. Educational Researcher, 48(5), 273-286. https://doi.org/10.3102/0013189X19852306

Duchesne, S., \& McMaugh, A. (2018). Educational psychology for learning and teaching. Cengage: Australia.

Elbeheri, G., Everatt, J., Theofanides, F., Mahfoudhi, A., \& Al Muhareb, K. (2018). Attitudes of academics to special needs accommodations in Kuwait. International Journal of Inclusive Education, 1-15. https://doi.org/10.1080/13603116.2018.1508517

Forlin, C., \& Chambers, D. (2011). Teacher preparation for inclusive education: Increasing knowledge but raising concerns. Asia-Pacific Journal of Teacher Education, 39(1), 17-32. https://doi.org/10.1080/1359866X.2010.540850

Forlin, C., Loreman, T., Sharma, U., \& Earle, C. (2009). Demographic differences in changing pre-service teachers' attitudes, sentiments and concerns about inclusive education. International Journal of Inclusive 
Education, 13(2), 195-209. https://doi.org/10.1080/13603110701365356

Hassanein, E. E. (2010). The inclusion of children with special educational needs in mainstream schools in Egypt (Unpublished doctoral dissertation). University of Exeter, UK.

Jordan, A. (2018). Supporting effective teaching project: 1. Factors influencing student success in inclusive elementary classrooms. Exceptionality Education International, 28(3), 10-27. Retrieved from http//ir.lib.uwo.ca/eei/vol28/iss $3 / 3$

Koutsouris, G., Anglin-Jaffe, H., \& Stentiford, L. (2019). How well do we understand social inclusion in education? British Journal of Educational Studies, 1-18. https://doi.org/10.1080/00071005.2019.1658861

Kuwait Ministry of Education. (2012). Special classes programme for slow learner children. [Brochure] Kuwait.

Majoko, T. (2016). Inclusion in early childhood education: Preservice teachers' voices. Early Child Development and Care, 186(11), 1859-1872. https://doi.org/10.1080/03004430.2015.1137000

Mngo, Z. Y., \& Mngo, A. Y. (2018). Teachers' perceptions of inclusion in a pilot inclusive education program: Implications for instructional leadership. Education Research International. https://doi.org/10.1155/2018/3524879

Norwich, B. (2013). Addressing tensions and dilemmas in inclusive education. Living in Uncertainty. Abingdon, England: Routledge. https://doi.org/10.4324/9780203118436

Oswald, M., \& Swart, E. (2011). Addressing South African pre-service teachers' sentiments, attitudes and concerns regarding inclusive education. International Journal of Disability, Development and Education, 58(4), 389-403. https://doi.org/10.1080/1034912X.2011.626665

Pallant, J. (2013). SPSS survival manual 5th edition: A step by step guide to data analysis using IBM SPSS.

Robson, C. (1993). Real world research: A resource for social scientists and practitioner-researchers. Oxford, England: Basil Blackwell.

Schwab, S., Nel, M., \& Hellmich, F. (2019). Social participation of students with special educational needs in mainstream education. New York, NY: Routledge.

Sharma, U., Moore, D., \& Sonawane, S. (2009). Attitudes and concerns of pre-service teachers regarding inclusion of students with disabilities into regular schools in Pune, India. Asia Pacific Journal of Teacher Education, 37, 319-331. http://doi.org/10.1080/13598660903050328

Sharma, U., Shaukat, S., \& Furlongers, B. (2015). Attitudes and self-efficacy of pre-service teachers towards inclusion in Pakistan. Journal of Research in Special Educational Needs, 15(2), 97-105. http://doi.org/10.1111/1471-3802.12071

Siuty, M. B. (2019). Teacher preparation as interruption or disruption? Understanding identity (re) constitution for critical inclusion. Teaching and Teacher Education: An International Journal of Research and Studies, 81(1), 38-49. https://doi.org/10.1016/j.tate.2019.02.008

Swain, K. D., Nordness, P. D., \&. Leader-Janssen, E. M. (2012). Changes in preservice teachers' attitudes toward inclusion, preventing school failure. Alternative Education for Children and Youth, 56(2), 75-81. https://doi.org/10.1080/1045988X.2011.565386

Toye, M. K., Wilson, C., \& Wardle, G. A. (2019). Education professionals' attitudes towards the inclusion of children with ADHD: The role of knowledge and stigma. Journal of Research in Special Educational Needs, 19(3), 184-196. https://doi.org/10.1111/1471-3802.12441

UNESCO (1994). The Salamanca statement and framework for action on special needs education. Paris, France: UNESCO.

UNESCO. (2017). A guide for ensuring inclusion and equity in education. Retrieved from http://unesdoc.unesco.org/images/0024/002482/248254e.pdf

Westwood, P. (2018). Inclusive and adaptive teaching: Meeting the challenge of diversity in the classroom. London: Routledge. https://doi.org/10.4324/9781351061261 


\section{Copyrights}

Copyright for this article is retained by the author(s), with first publication rights granted to the journal.

This is an open-access article distributed under the terms and conditions of the Creative Commons Attribution license (http://creativecommons.org/licenses/by/4.0/). 